\title{
REPRESENTAÇÕES SOBRE ORALIDADE E ESCRITA NA TRADIÇÃO AFRICANA E SUA PRESENÇA/AUSÊNCIA NA FORMAÇÃO EDUCACIONAL BRASILEIRA
}

\author{
Débora Cristina de Araujo ${ }^{1}$
}

Resumo: São diversos estudos sobre oralidade e escrita que atribuíram à segunda condição de superioridade à segunda. Nessa lógica, a escrita seria capaz de desenvolver habilidades cognitivas mais abstratas que a oralidade. No caso do Brasil, a oralidade associada à cultura africana é apresentada nessa mesma lógica inferiorizante, refletindo tal processo na formação escolar. Torna-se imprescindível uma reflexão sobre a necessidade de valorização de culturas com fortes marcas da oralidade e a superação de um modelo curricular eurocêntrico.

Palavras-chave: Oralidade e escrita. Hierarquização. Tradição oral africana. Griots.

\section{REPRESENTATIONS ABOUT ORALITY AND WRITING IN THE AFRICAN \\ TRADITION AND ITS PRESENCE/ABSENCE IN THE BRAZILIAN \\ EDUCATIONAL TRAINING}

\begin{abstract}
There are several studies on orality and writing that attributed to the second condition of superiority to the second. In this logic, the writing would be able to develop more abstract cognitive abilities than orality. In Brazil, orality associated with African culture is presented in the same logic of inferiority, reflecting that process in school education. It is essential to reflect on the need to value cultures with strong brands of orality and overcoming a Eurocentric curriculum model.

Keywords: Orality and writing. Hierarchy. African oral tradition. Griots.
\end{abstract}

\section{INTRODUÇÃO}

Costuma-se associar as culturas de matrizes orais ao primitivismo, como sendo a característica que as diferenciaria dos povos "civilizados" ou "letrados". Este artigo busca refletir sobre isso: em que medida as manifestações da língua em dimensão oral ou dimensão escrita podem ser classificadas como superiores ou inferiores? E mais: quais são os motivos que relegaram historicamente a tradição oral africana presente no Brasil à condição de representante de saberes primitivos?

1 Pesquisadora do Núcleo de Estudos Afro-Brasileiros, da Universidade Federal do Paraná (UFPR). Doutora em Educação (UFPR), especialista em Língua Portuguesa e Literaturas (UNESPAR — Campus de Paranavai), professora de Língua Portuguesa na rede estadual do Paraná. E-mail: debbora.a@hotmail.com. 
Para tanto, este texto apresentará inicialmente estudos que oscilaram em investigações mais ou menos eticamente comprometidas, propondo que ora a escrita seria capaz de desenvolver habilidades cognitivas mais abstratas que a oralidade, e ora refutando tal argumento por identificar que pesquisas como estas se fundamentam em bases etnocêntricas. A segunda parte do artigo tratará de elementos que realçam a importância da oralidade para os povos africanos, categorizada como "tradição oral africana", e da qual o escritor e etnólogo maliense Amadou Hampaté Bâ $(2003 ; 2010)$ foi um pesquisador expoente. Nessa parte também será analisado como tal tradição deixada (forçosamente em decorrência do sequestro de populações africanas para o Brasil) como herança para a cultura brasileira foi e é historicamente desvalorizada, sobretudo no ambiente escolar e no currículo, que a relegam a espaços e representações de folclorização ou inferioridade.

O desafio é, portanto, refletir sobre o necessário e urgente re-estabelecimento das dimensões sociais, culturais, históricas e religiosas da tradição oral africana no Brasil como forma de propor novas bases para a formação educacional brasileira que negou, ao longo dos séculos, essa história, produzida pela presença e influência africana no país.

\section{Oralidade e escrita: uma querela conceitual}

Diversas definições da importância da escrita como exclusivo elemento civilizador foram desenvolvidas pela produção intelectual ocidental. Em uma extensa revisão sobre o assunto, Ana Maria de Oliveira Galvão e Antônio Augusto Gomes Batista (2006) apresentam vários estudos de autores/as que investiram suas pesquisas na busca pela compreensão da oralidade como aspecto primário e anterior à escrita,"por meio de trabalhos de campo, sobre sociedades ainda orais, buscando vestígios daquilo que se convencionou denominar oralidade primária" (GALVÃO; BASTISTA, 2006, p. 405).

Um deles, Walter Ong (1998 apud GALVÃO; BASTISTA, 2006), foi Um dos pioneiros a classificar a oralidade em duas categorias: a oralidade primária e a secundária. A primeira referir-se-ia à manifestação puramente oral, presente em grupos humanos que não tiveram nenhuma forma de contato com a escrita. Em outras palavras, refere-se às "culturas intocadas pelo letramento ou por qualquer conhecimento da escrita ou da imprensa ou, ainda, a das pessoas totalmente não familiarizadas com a escrita" (GALVÃO; BASTISTA, 2006, p. 408). Já a oralidade secundária tem mais relação com o mundo ocidental, em que esta se torna depen- 
dente da imprensa, da televisão, do rádio e de outras formas de comunicação. Obviamente para Ong não há mais sociedades com a presença da oralidade primária, mas isso não o impediu de elaborar um arcabouço teórico para entender e representar culturas com tal característica. Sua abordagem parte do princípio de que a relação essencial para estes grupos é o som, que assume o caráter de único responsável pela representação das palavras, já que não há outras formas de descrevê-las.

Outros pontos levantados por Ong são no sentido de enfatizar que "nas sociedades orais, há um grande investimento de energia na transmissão da cultura de geração a geração. O conhecimento tem que ser continuamente repetido para que as novas gerações possam, 'arduosamente', aprender” (GALVÃO; BATISTA, 2006, p. 411). De certa forma, ao desenvolver essa análise, o autor aponta para a importância das narrativas nas sociedades tradicionais e como a sua elaboração e transmissão para as novas gerações implica manejo de elementos do enredo: “[...] a cada narração, deve-se dar à história, de uma maneira única, uma situação singular, pois nas culturas orais o público deve ser levado a reagir, muitas vezes intensamente" (ONG, 1998 apud GALVÃO; BATISTA, 2006, p. 409). Tais características, segundo o autor, direcionam seus estudos para uma conclusão: o pensamento oral é mais concreto e situacional, ou seja, capacidades mais elaboradas de abstração são impossibilitadas a sociedades predominantemente orais.

Nesta mesma perspectiva, outros/as pesquisadores/as ratificaram características que evidenciariam as dificuldades de abstração do pensamento oral:

Cook-Gumperz e Gumperz [...] afirmam que existem diferentes estratégias de racionalização. Ao contrário das pessoas letradas, as não letradas, no geral, não descontextualizam os problemas: o modo de racionalidade das primeiras seria 'teórico', enquanto o das segundas 'empírico’(GALVÃO; BATISTA, 2006, p. 414).

Embora bastante análogas das práticas sociais, em que a oralidade e a escrita assumem dimensões dinâmicas, análises como essas sobre a hierarquização entre oralidade e leitura em que a última ocupa lugar de destaque por ser, supostamente, a única responsável pela capacidade de abstração - remete a uma discussão presente nas sociedades grafocêntricas de hoje, como a brasileira: a alfabetização é considerada um dos elementos essenciais para o efetivo exercício da cidadania. Magda Soares (2004, p. 55), porém, ressalta que "a vinculação entre alfabetização e cidadania faz parte do senso comum”. Sua proposta parte do pressuposto de que a conquista da alfabetização não garante, necessariamente, a conquista da cidadania e do acesso aos bens historicamente produzidos pela humanidade. Podemos, neste sentido, infe- 
rir que a "descontextualização dos problemas" das pessoas letradas, como propõem CookGumperz e Gumperz, não tem a ver com a capacidade mental, mas sim com o entendimento que se tem sobre oralidade e escrita inseridos em cada cultura. Soares ainda destaca:

[...] o valor e a importância da alfabetização não são inerentes a ela, mas dependem da função e dos usos lhe são atribuídos no contexto social. Atribuir à alfabetização um valor positivo absoluto revela uma visão etnocêntrica: estudos antropológicos e estudos históricos têm apontado o fato de que, a língua escrita é, muitas vezes, vista mais como um mal que como um bem (SOARES, 2004, p. 58).

Diante disso (e à parte a obviedade), até que ponto as conclusões sobre a incapacidade de o pensamento oral desenvolver estratégias cognitivas mais elaboradas são realmente comprovadas? Galvão e Batista (2006), ainda em sua revisão de literatura sobre o assunto, indicam outras perspectivas teóricas que visaram investigar com mais profundidade as diferenças e convergências entre os processos cognitivos que envolvem o uso da escrita e o uso da oralidade. Para Harvey Graff (1987 apud GALVÃO; BATISTA, 2006, p. 424), por exemplo, a divisão tradicional entre oralidade e escrita nos moldes das grandes pesquisas realizadas sobre o assunto não deve ser considerada uma verdade inquestionável. Sua posição frente à importância da escrita sobre a oralidade assemelha-se a de Soares (2004) pois considera que, segundo informam Galvão e Batista (2006, p. 424),"’a cultura escrita tem diferentes significados, que variam em razão de seus modos de aquisição, papéis e usos, para membros de diferentes continentes, regiões, estados ou mesmo grupos".

Por fim, Graff analisa que por trás de um "mito do letramento" há uma concepção idealizada de sociedade que seria fruto de correlações que associam diretamente a cultura da escrita "ao crescimento econômico, à industrialização, à estabilidade política, à participação democrática, à urbanização, ao consumo e, ainda, à contracepção" (GALVÃO; BATISTA, 2006, p. 424). Não se trata de negar, segundo o autor, as aproximações e possíveis consequências da cultura da escrita, mas sim de relativizar essa condição que se convencionou, como argumenta Soares (2004), como um pré-requisito para o exercício da cidadania.

Outro autor que corrobora a afirmação de que não existe uma hierarquia entre oralidade e escrita é Brian Street (1995 apud GALVÃO; BATISTA, 2006). Ele propõe que não se pode ignorar - como afirma que fez Ong em seus estudos — os aspectos históricos, políticos, sociais, econômicos, entre outros, os quais exercem influência na cultura de um grupo. Para Street não basta apenas analisar os contextos de letramento, mas sim estabelecer, quando se pretende desenvolver pesquisa sobre o assunto, ligações com outros elementos: a análise do discurso e a abordagem etnográfica, por exemplo. 
Diante de tais considerações, a pergunta apresentada na introdução deste artigo é recuperada: em que contextos e sob quais perspectivas a escrita está sendo considerada superior à oralidade? Retomando a discussão sobre o acesso à leitura e a escrita como exercício de cidadania, é necessária uma análise muito mais complexa e inserida nos contextos sociais. É o que argumenta Soares (2004, p. 58):

\begin{abstract}
As sociedades modernas, porém, são fundamentalmente grafocêntricas; nelas, a escrita está profundamente incorporada à vida política, econômica, cultural, social, e é não só enormemente valorizada, mas, mais que isso, é mitificada (é frequente, por exemplo, a suposição de que na escrita é que está o discurso da verdade, que só a escrita é o repositório do saber legítimo). Neste contexto, a alfabetização é um instrumento necessário à vivência e até mesmo à sobrevivência política, econômica, social $[\ldots]$.
\end{abstract}

Dizer, inicialmente, que alfabetização (que neste texto relaciona-se diretamente com a escrita) como pré-requisito para o exercício da cidadania faz parte do senso comum não significa negar, para Soares, a sua importância e necessidade para uma sociedade grafocêntrica, onde as relações de poder imperam sobre o conhecimento sistematizado por meio do processo de escolarização. Nas palavras da autora:

[...] o acesso à leitura e à escrita, como acesso a condições de possibilidade de participação social e cultural, é, fundamentalmente, um processo político, através do qual grupos excluídos dos direitos sociais, civis e políticos e dos privilégios culturais têm acesso a um bem simbólico que lhes é sonegado e que é um capital indispensável na luta pela conquista desses direitos e desses privilégios, na luta pela participação no poder [...]. Justifica-se, assim, a afirmação de que a alfabetização é um instrumento na luta pela conquista da cidadania, e é fator imprescindível ao exercício da cidadania (SOARES, 2004, p. 59, grifos da autora).

Talvez seja essa observação que tenha faltado a pesquisas como de Ong, Jenny CookGumperz e John Gumperz: o conhecimento de que a escrita pode representar o exercício da cidadania e promover abstrações mentais por parte dos grupos que a utilizam, não por ser mais complexa que a oral (como veremos mais adiante), mas por ter outro significado em sociedades grafocêntricas: ser uma ferramenta essencial para a conquista de direitos ou de poder.

Luiz Antonio Marcuschi (2001), analisando pesquisas realizadas com crianças senegalesas e siberianas produzidas por renomados/as autores/as da psicologia do desenvolvimento como Vigotski e Piaget dentre outros/as, identifica fortes traços de etnocentrismo, embora na perspectiva deste artigo poderiam ser muito melhor caracterizados como marcas do "racismo epistêmico" pois, conforme define Ramón Grosfoguel (2007), esse conceito “considera os conhecimentos não-ocidentais como inferiores aos conhecimentos ocidentais" (GROSFO- 
GUEL, 2007, p. 32). Para Marcuschi, estudos comparativos sobre a aquisição da leitura por parte de povos "ágrafos" ou a comparação entre grupos letrados e iletrados:

[...] não atestam absolutamente nada em relação à incapacidade de povos ágrafos pensarem logicamente. Mostram apenas que esses povos não possuem a nossa maneira de raciocinar e que nisso diferem de nós, mas não comprovam que não tenham um tipo de raciocínio abstrato, reflexivo e lógico. [...] No meu entender, todas as investigações levadas a efeito nesse terreno são etnocêntricas, perigosas e epistemologicamente equivocadas, para dizer o mínimo. No fundo, o que propiciam é simplesmente um instrumento cada vez mais convincente de dominação cada vez mais absoluta pelo argumento da superioridade cognitiva de um tipo de pensamento tido como mais elevado e científico (MARCUSCHI, 2001, p. 60-61).

Embora epistemologicamente racistas (ou etnocêntricos, como argumenta o autor), estudos como estes se solidificaram na formação média de grande parte das sociedades ocidentais e atuaram e continuam atuando para ratificar a ideia de inferioridade e superioridade entre grupos humanos a partir de uma maior ou menor aproximação com a escrita e com a oralidade. E assim a escrita que foi, continua sendo "um instrumento de dominação e imposição dos letrados sobre os demais. Ela operou e opera como um instrumento de segregação e demarcação de desigualdades, de modo que suas consequências são diversificadas" (MARCUSCHI, 2001, p. 49).

Observando na sociedade brasileira como a cultura oral de povos historicamente subalternizados vem sendo apresentada, verifica-se a necessidade de estudos nesse sentido. A próxima parte deste artigo tem o objetivo de discutir sobre a cultura oral africana presente no Brasil. Antes, no entanto, serão apresentados importantes elementos da tradição oral no continente africano.

\section{2 oralidade: um referencial africano e uma herança afro-brasileira}

O caráter evolucionista atribuído por diversos/as pesquisadores/as aos processos de comunicação humana incutiu nos estudos sobre língua e linguagem, como já exposto neste artigo, a ideia de que a oralidade localiza-se num estágio inicial da história, sendo a escrita a conquista do desenvolvimento e do progresso. Essa conclusão repercutiu/repercute de tal modo que se estabeleceram classificações hierarquizadas entre os grupos que utilizam predominantemente a escrita e os que têm na oralidade seu referencial sócio-histórico.

Outro aspecto ignorado na maior parte dos estudos sobre a oralidade foi a análise de que a paralinguística como representação (não apenas de aspectos gráficos, mas também de um 
conjunto de elementos utilizados na oralidade — voz, gestos, persuasão do interlocutor, informações mnemônicas) são extremamente complexos e, portanto, podem exigir um alto grau de abstração mental. Dessa maneira, não é possível estabelecer, com rigor científico, que a escrita exija mais empenho das capacidades mentais como quiseram muitos estudiosos evolucionistas destacados por Galvão e Batista (2006).

Sobre isso, Marcuschi (2001) defende que "[t]omando oralidade e escrita como duas variáveis e não como propriedades, estaremos em condições de analisar as operações cognitivas dos mais diversos povos e sociedades sem atribuir-lhes aprioricamente algum tipo de característica avaliativa” já que "oralidade escrita são modos complementares de tratar e compreender o mundo e não duas atividades essencialmente diversas a ponto de podermos imaginar que quem não dispõe da escrita não dispõe de alguns recursos mentais que os letrados conseguiram atingir" (MARCUSCHI, 2001: p. 45).

Analisando a tradição oral africana, Amadou Hampaté Bâ (2010) ressalta na figura do "tradicionalista" características mnemônicas extraordinárias, considerando sua principal função: arquivista. "Guardião dos segredos da Gênese cósmica e das ciências da vida, o tradicionalista, geralmente dotado de uma memória prodigiosa, normalmente também é o arquivista de fatos passados transmitidos pela tradição, ou de fatos contemporâneos" (HAMPATÉ BÂ, 2010, p. 175).

No entanto, o autor lembra como houve na África em período de dominação colonial uma forte perseguição aos tradicionalistas por serem reconhecidos como detentores de conhecimentos locais e que ameaçariam a dominação que também se fez no campo ideológico. Assim, o colonizador:

[...] procurava extirpar as tradições locais a fim de implantar suas próprias ideias, pois, como se diz, 'Não se semeia nem em campo plantado nem em terra alqueivada'. Por essa razão, a iniciação geralmente buscava refúgio na mata e deixava as grandes cidades, chamadas de Tubabudugu, 'cidades de brancos'(ou seja, dos colonizadores) (HAMPATÉ BÂ, 2010, p. 176).

Partindo das tradições da savana ao sul do Saara, o autor apresenta importantes características sobre a oralidade tomada como uma função social de alta importância, seja no campo religioso, político, lúdico, dentre outros. Um aspecto marcante demonstrado em sua pesquisa é a complexidade da tradição oral na organização social dos povos e, portanto, a necessidade de se preservar essa tradição longe de cidades Tubabudugu. A "Palavra" (Kuma), na tradição bambara no Mali, por exemplo,"é uma força fundamental que emana do próprio Ser Supremo, 
Maa Ngala, criador de todas as coisas. Ela é o instrumento da criação: “Aquilo que Maa Ngala diz, é!", proclama o chantre do deus Komo" (HAMPATÉ BÂ, 2010, p. 170, grifos do autor). Conta o mito de criação que Maa Ngala sentia falta de um interlocutor. Depois de várias tentativas criou o ser humano, Maa.

Síntese de tudo o que existe, receptáculo por excelência da Força suprema e confluência de todas as forças existentes, Maa, o Homem, recebeu de herança uma parte do poder criador divino, o dom da Mente e da Palavra.

$[\ldots]$

A tradição africana, portanto, concebe a fala como um dom de Deus. Ela é ao mesmo tempo divina no sentido descendente e sagrada no sentido ascendente (HAMPATÉ BÂ, 2010, p. 171-172, grifos do autor).

Partindo de explicações como essa, é possível para nós, ocidentais, ao menos nos aproximarmos de uma rasa compreensão da ideia de que: "o que a África tradicional mais preza é a herança ancestral. O apego religioso ao patrimônio transmitido exprime-se em frases como: 'Aprendi com meu Mestre', 'Aprendi com meu pai', 'Foi o que suguei no seio de minha mãe' (HAMPATÉ BÂ, 2010, p. 174).

Outro elemento importante destacado pelo autor é a diferenciação entre os tradicionalistas "Conhecedores" dos tradicionalistas "Griots". Pode-se dizer que aos primeiros são atribuídas funções bem mais ritualísticas que aos segundos. Os Conhecedores ${ }^{2}$, são geralmente mestres iniciados e iniciadores de um ramo específico (embora não sejam definidos como “especialistas” pois na tradição africana, argumenta o autor, não há segmentação de aspectos da vida).

Por exemplo, um mesmo velho conhecerá não apenas a ciência das plantas (as propriedades boas ou más de cada planta), mas também a 'ciência das terras'(as propriedades agrícolas ou medicinais dos diferentes tipos de solo), a 'ciência das águas', astronomia, cosmogonia, psicologia, etc. Trata-se de uma ciência da vida cujos conhecimentos sempre podem favorecer uma utilização prática (HAMPATÉ BÂ, 2010, p. 175).

Já no que se refere aos Griots, termo francês popularizado em substituição de Dieli em língua bambara - , ou em língua fulani de Nyamakala (nomenclatura geral, ou Nyeeybe, quando membro de uma casta), a formação exige outros critérios que não envolvem processos iniciáticos. Por exemplo: elementos como a autenticidade da transmissão é a principal característica do processo formativo de um Conhecedor. "Para eles, a mentira não é simplesmente

2 "Em bambara, chamam-nos de Doma ou Soma, os 'Conhecedores', ou Donikeba, 'fazedores de conhecimento'; em fulani, segundo a região, de Silatigui, Gando ou Tchiorinke, palavras que possuem o mesmo sentido de 'Conhecedor'” (HAMPATÉ BÂ, 2010: 175). 
um defeito moral, mas uma interdição ritual cuja violação lhes impossibilitaria o preenchimento de sua função" (HAMPATÉ BÂ, 2010, p. 177), considerando que a mentira corrompe os rituais dos quais um Conhecedor exerce, já que sua função é sagrada. Especialmente os Conhecedores Doma,"os grandes detentores da palavra", fundamentam-se no princípio da verdade e da idoneidade dos fatos narrados. O autor ressalta, na personalidade dos Doma, a disciplina no uso da palavra e o cuidado para não proferi-la imprudentemente.

Já no caso dos Dieli (Griots) "a disciplina da verdade não existe; [...] a tradição lhes concede o direito de travesti-la ou de embelezar os fatos, mesmo que grosseiramente, contanto que consigam divertir ou interessar o público. 'O griot', como se diz, 'pode ter duas línguas"” (HAMPATÉ BÂ, 2010, p. 178). A complexidade em torno da imagem do Griot extrapola os limites deste artigo, já que a controvérsia e a ambiguidade são marcas características desse importante contador/cantador de histórias. O que cabe salientar é que há diferentes funções atribuídas aos Griots: os griots músicos são cantores, instrumentistas e destacam-se por transmitir músicas antigas além de comporem outras; os griots "embaixadores" e cortesãos estão ligados a uma família nobre ou real e são responsáveis pela mediação de desavenças entre grandes famílias; os griots genealogistas, historiadores ou poetas — ou exercendo as três funções - são os grandes contadores de histórias, transformando-os em grandes viajantes e pesquisadores de novas histórias.

Embora a verdade, como apresentado anteriormente, não seja uma premissa da função do Griot e em decorrência disso nem sempre suas palavras sejam consideradas como expressões verídicas, são palavras frequentemente respeitadas pois "a tradição aceita as invenções dos dieli, sem se deixar enganar, pois, como se diz, eles têm a 'boca rasgada"' (HAMPATÉ BÂ, 2010, p. 193). E eles assumem, dentre outros, um papel essencial como portadores de notícias ou motivadores para o enfrentamento de grandes dificuldades:

Os griots foram importante agente ativo do comércio e da cultura humana. Em geral dotados de considerável inteligência, desempenhavam um papel de grande importância na sociedade tradicional do Bafur devido à sua influência sobre os nobres e os chefes. Ainda hoje, em toda oportunidade, estimulam e suscitam o orgulho do clã dos nobres com suas canções, normalmente para ganhar presentes, mas muitas vezes para também encorajá-los a enfrentar alguma situação difícil. [...]

Os griots tomaram parte em todas as batalhas da história, ao lado de seus mestres, cuja coragem estimulavam relembrando-lhes a genealogia e os grandes feitos dos antepassados. Para o africano, a invocação do nome de família é de grande poder. Ademais, é pela repetição do nome da linhagem que se saúda e se louva um africano (HAMPATÉ BÂ, 2010, p. 195-196).

Pela análise do autor é possível ainda inferir sobre outra categoria de griot: os Griotrei (ou Griots-Doma),"'a quem as pessoas consultam por sua sabedoria e seu conhe- 
cimento, e que, embora capaz de divertir, jamais abusa de seus direitos consuetudinários" (HAMPATÉ BÂ, 2010, p. 198). São formados a partir dos conhecimentos adquiridos como um Doma se as suas aptidões permitirem e se ele for iniciado (com exceção da iniciação do Komo pois esta lhe é proibida já que se trata de iniciação destinada apenas aos mestres ferreiros,). Assim, os Griots-reis são detentores de grande respeito sobretudo por focarem a idoneidade dos fatos relatados, ainda que as demais categorias de griots também sejam bastante valorizadas, já que dele "se pode esperar alguns embelezamentos da verdade, com a intenção de destacar o papel desta ou daquela família - embelezamentos que não seriam feitos por um tradicionalista-doma, que se interessa, acima de tudo, pela transmissão fiel" (HAMPATÉ BÂ, 2010, p. 198)

Refletindo sobre a importância da tradição oral no contexto africano — que "não se resume à transmissão de narrativas ou de determinados conhecimentos", pois é "geradora e formadora de um tipo particular de ser humano" (HAMPATÉ BÂ, 2010, p. 189 , grifos do autor) - é de extrema relevância analisar como essa herança se desenvolveu no Brasil, um dos países mais negros do mundo, e quais os valores simbólicos atribuídos a ela.

Ao abordar especialmente a presença africana no país, é possível identificar a pouca valorização de tal herança e um processo de hierarquização naturalizada pela lógica de que os conhecimentos de origem africana - sobretudo aqueles transmitidos pela oralidade - eram menores, tornando-se, inclusive, senso comum. Isso se deve, em grande medida, à equivocada ideia de que os povos africanos sequestrados para o Brasil eram ágrafos. Henrique Cunha Júnior3, em palestra proferida em 2008, com o título "Sabiam escrever os escravizados no Brasil: discutindo conceitos e preconceitos sobre o conhecimento", argumenta que diversos grupos étnicos na diáspora africana detinham o domínio da escrita muito antes de seus escravizadores. Une-se a tais dados o reconhecimento de que a escrita foi uma atividade alijada da história convencionada sobre a África, quando na verdade, o continente africano detém algumas das matrizes da escrita, conforme apresenta Elisa Larkin Nascimento (2008, p. 34): "Além dos hieróglifos egípcios, existem vários sistemas de escrita desenvolvidas por outros povos africanos antes da invasão muçulmana, que introduziria a escrita árabe".

Como consequência de hierarquizações, a tradição oral foi relegada aos espaços e grupos marginalizados da sociedade cujos conhecimentos e heranças culturais transmitidos oralmente foram estigmatizados, juntamente com seus/as contadores/as. Basta rememorarmos a imagem da Tia Nastácia, de Monteiro Lobato:

Histórias da Tia Nastácia

[...] E tia Nastácia rematou a história repetindo o mesmo finzinho de sempre: 'E eu lá estive e trouxe um prato de doces, que caiu na ladeira'.

Entrou por uma porta

Saiu por um canivete;

Manda o rei meu senhor

Que me conte sete.

— Que história de contar sete é essa? — perguntou Emília quando a negra chegou ao fim.

— Não estou entendendo nada.

— Mas isto não é para entender, Emília — respondeu a negra. — É da história. Foi assim que minha mãe Tiaga me contou o caso da princesa ladrona, que eu passo adiante do jeito que recebi.

3 Palestra proferida no V Encontro do Fórum Permanente de Educação e Diversidade Étnico-Racial do Paraná (FPEDER), realizado em Paranavaí, no dia 13/04/2008. Mais informações sobre o assunto estão em Cunha Jr (2005). 
— E esta! — exclamou Emília olhando para dona Benta.

- As tais histórias populares andam tão atrapalhadas que as contadeiras contam até o que não entendem.

- Esses versinhos do fim são a maior bobagem que ainda vi. Ai meu Deus do céu! Viva Andersen! Viva Carroll!

— Sim — disse dona Benta. — Nós não podemos exigir do povo o apuro artístico dos grandes escritores. O povo... Que é o povo? São essas pobres tias velhas, como Nastácia, sem cultura nenhuma, que nem ler sabem e que outra coisa não fazem senão ouvir as histórias de outras criaturas igualmente ignorantes, e passá-las para outros ouvidos, mais adulterados ainda.

$[\ldots]$

- Pois cá comigo - disse Emília - só aturo essas histórias como estudos da ignorância e burrice do povo. Prazer não sinto nenhum. Não são engraçadas, não têm humorismo. Parecem-me muito grosseiras e bárbaras - coisa mesmo de negra beiçuda, como tia Nastácia. Não gosto, não gosto e não gosto... (LOBATO, 1982, p. 18-19).

Dessa maneira foi-se construindo o imaginário coletivo sobre elementos da tradição africana em contextos literários no Brasil. A valorização de outra cultura como sendo sua e a efetiva negação da sua (já constituída com a presença da população afro-brasileira) transformaram-se na receita infalível para o enfraquecimento da oralidade, sobretudo de matrizes africanas e indígenas, como sendo duas das possíveis e legítimas manifestações da literatura oral no Brasil. No contexto específico da personagem de Tia Nastácia, refleti (ARAUJO, 2015) sobre o explícito investimento de Lobato na pesquisa de narrativas e mitos afrobrasileiros e as condições de fala atribuídas à referida personagem, sempre ou grande parte das vezes, desvalorizadas pelas demais personagens.

Ao atribuir à Tia Nastácia (sobretudo a ela por ela ser frequente nas tramas desenvolvidas no Sítio), características de conhecedora das crendices populares e das narrativas tradicionais, o autor imerge no universo afro-brasileiro, sincretizado com as culturas indígenas e europeias, revelando-se um exímio folclorista. [...]

Chama a atenção, [...] [no entanto], a opção do autor em retratar essa personagem e seus conhecimentos pelo viés da inferioridade e do exotismo diante da outra possibilidade que era de apresentá-los em lógicas mais altivas e alteras (ARAUJO, 2015, p. 101-102).

Essa é apenas uma amostra dos processos que constituíram e fortaleceram a representação da oralidade como manifestação da língua inferior à escrita no contexto brasileiro. Ratifica-se, como em sociedades ocidentais como a brasileira, o quanto membros de uma sociedade grafocêntrica que passaram pelo ambiente escolar e que têm a escrita como eixo civilizatório foram privados dos conhecimentos transmitidos (também historicamente) pela oralidade, ou melhor, pela literatura oral, relegada ao plano folclórico. E, dessa forma, a oralidade - ao não fazer parte do rol de conhecimentos elencados para compor o currículo - por ser tratada com um saber folclorizado, ocupa um segundo plano nos estudos escolares. 
Porém, considerando que aberturas e possibilidades estejam sendo implementadas por meio de ações pedagógicas que buscam inserir os saberes indígenas, afro-brasileiros e africanos por meio da Educação das Relações Étnico-Raciais ${ }^{4}$, faz-se necessário construir uma análise teórica para avaliar a importância da literatura oral para a formação escolar.

Levando-se em conta os fatores que tornam o ato de contar histórias um gênero literário e, portanto, um referencial importante para o desenvolvimento do/a leitor/a-ouvinte, torna-se relevante atentarmos especialmente para dois aspectos que ele tem de mais genuíno: é um gênero da área da fruição, do entretenimento, e é também uma forma de valorização e difusão de conhecimentos históricos, sociais, linguísticos, dentre outros. Por mais que a literatura escrita também possua tais características, é especialmente através do contato direto entre locutor/a e interlocutor/a que se estabelecem elos emotivos e sensoriais, de modo tão peculiar que expressões de medo, de surpresa ou alegria sejam tão evidentes nos rostos de quem ouve as histórias. A “oralitura”, proposta por Leda Maria Martins (2006) pode enfatizar essa discussão:

\begin{abstract}
O termo oralitura, da forma como o apresento, não nos remete univocamente ao repertório de formas e procedimentos culturais da tradição linguística, mas especificamente ao que em sua performance indica a presença de um traço cultural estilístico, mnemônico, significante e constitutivo, inscrito na grafia do corpo em movimento e na vocalidade. Como um estilete, esse traço inscreve saberes, valores, conceitos, visões de mundo e estilos. Se a oratura nos remete a um corpus verbal, indiretamente evocando sua transmissão, a oralitura é do âmbito da performance, sua âncora; uma grafia, uma linguagem, seja ela desenhada na letra performática da palavra ou nos volejos do corpo (MARTINS, 2006, p. 84).
\end{abstract}

Em se tratando essencialmente do Brasil e da sua produção literária, a adoção de medidas que tendem a valorizar a literatura oral, sobretudo a afro-brasileira e indígena, são essenciais haja vista a influência eurocêntrica que por séculos impôs seus moldes, minimizando a cultura nacional. Juan Delval (2001) diz que a escola, ao desconsiderar o conhecimento narrativo como vem fazendo, acaba inserindo de modo abrupto o conhecimento científico sem contextualização ao sistema educacional. Do mesmo modo, ele reconsidera a importância do conhecimento narrativo afirmando que "não é simplesmente um conhecimento concreto, limitado a esse espaço e a esse tempo, mas tem um valor mais universal” (DELVAL, 2001, p. 66).

4 Preconizada por um conjunto de leis e documentos oficiais: Leis 10.639/2003 e 11.645/2008, que alteram os artigos 26A e 79B da Lei de Diretrizes e Bases da Educação Nacional, tornando obrigatório, nos estabelecimentos públicos e privados da Educação Básica, o estudo da história e cultura afro-brasileira e indígena, dentre outros documentos. 
Nessa perspectiva, conhecer as literaturas orais indígenas, afro-brasileiras (e, por extensão as africanas), significa ter acesso aos conhecimentos produzidos por povos ancestrais e que deram origem à civilização humana. Sobre isso, o autor afirma:

Quando apareceu a escrita, no Oriente Próximo e no Egito, mais de três mil anos antes de nossa era, elas começaram a ser registradas por escrito. Encontramos narrações literárias na Mesopotâmia e no Egito nos primeiros textos que foram conservados, e o fato de que, com o surgimento da escrita, foram escritas histórias bastante elaboradas mostra que possivelmente existiam muito antes e eram transmitidas via oral. Parece que essas narrações tinham um êxito notável, e os egípcios, por exemplo, gostavam muito delas. Um bom narrador era uma pessoa que gozava de prestígio (DELVAL, 2001, p. 61).

Urge, portanto, o reconhecimento de que a oralidade, como matriz civilizatória de diversos povos, dentre eles africanos e indígenas, deva compor com mais ênfase o currículo escolar e os estudos literários. Essa abordagem pode contribuir para o entendimento da própria história do país por proporcionar visibilidade a aspectos culturais, científicos, econômicos e sociais de grupos humanos fundantes da população brasileira e que foram relegados à condição de folclore no processo de escolarização formal.

Nilma Lino Gomes (2006) propõe o enfrentamento da "noção hegemônica de conhecimento que impera na escola, levando-nos a refletir sobre a tensa e complexa relação entre esta noção e os outros saberes que fazem parte do processo cultural e histórico no qual estamos imersos" (GOMES, 2006, p. 24). E nessa complexa relação está a dicotomia hierarquizada entre oralidade e escrita, em que a primeira é subjugada duplamente no contexto brasileiro: por sugerir anterioridade ou atraso em relação ao "progresso" estimulado pela escrita, e por compor-se como uma matriz característica afro-brasileira e indígena, ou seja,"primitiva" no sentido mais abjeto possível.

Essa possibilidade pode representar o reconhecimento de contadores e contadoras de histórias como Tia Nastácia, não mais como responsáveis pela perpetuação da "ignorância e burrice do povo", como propunha Lobato, mas sim como grandes Griots, representando-se como realmente são: exímios/as menestréis da arte de contar, cantar e encantar.

\section{Reflexões finais}

O objetivo deste texto foi discutir como a construção histórica que hierarquizou os conceitos de oralidade e escrita foi responsável por também hierarquizar os grupos humanos, 
classificando povos que têm como base cultural a oralidade como sendo primitivos ou incivilizados. Diversas pesquisas sobre culturas, com explícitas perspectivas epistemologicamente racistas, imperaram por décadas como verdades absolutas acerca da capacidade de abstração mental que a escrita supostamente proporciona em detrimento da oralidade.

No caso do Brasil, além de produzir tais informações errôneas e equivocadas, esta classificação foi responsável por relegar, nos estudos literários, a cultura oral ao caráter folclórico. E sendo a tradição africana responsável por grande parte da representação desta oralidade, consequentemente os valores e saberes dos povos que aqui se perpetuaram foram desconsiderados como conhecimentos sistematizados.

Reconsiderar a posição da oralidade vai muito além do reconhecimento de culturas como a indígena, afro-brasileira e africana como bases fundamentais da história e cultura brasileira. Tem a ver, também, com a superação de um modelo hegemônico hierarquizante que ao longo dos séculos tem enfatizado uma "visão restrita de conhecimento, ignorando e até mesmo desprezando outros conhecimentos, valores, interpretações da realidade, de mundo, de sociedade e de ser humano acumulados pelos coletivos diversos" (GOMES, 2006, p. 36). Tornase um exercício urgente e necessário à sociedade brasileira como forma de contribuir para importantes transformações sociais e para a construção de uma efetiva educação justa, democrática e antirracista.

\section{Referências}

ARAUJO, Débora Cristina de. Literatura infantil e política educacional: estratégias de racialização no Programa Nacional de Biblioteca da Escola (PNBE). Tese (Doutorado em Educação). Universidade Federal do Paraná, 2015.

BRASIL. Presidência da República. Lei 10.639, de 9 de janeiro de 2003. Altera a Lei ${ }^{\circ}$ 9.394, de 20 de dezembro de 1996, que estabelece as diretrizes e bases da educação nacional, para incluir no currículo oficial da Rede de Ensino a obrigatoriedade da temática "História e Cultura Afro-Brasileira", e dá outras providências. Diário Oficial da União. Brasília, DF, 10 jan. 2003, p. 1.

BRASIL. Presidência da República. Lei 11.645, de 10 de março de 2008. Altera a Lei no 9.394, de 20 de dezembro de 1996, modificada pela Lei no 10.639, de 9 de janeiro de 2003, que estabelece as diretrizes e bases da educação nacional, para incluir no currículo oficial da rede de ensino a obrigatoriedade da temática "História e Cultura Afro-Brasileira e Indígena". Diário Oficial da União. Brasília, DF, 11 mar. de 2008, p. 1. 
CUNHA JR., Henrique. Nós, afrodescendentes: história africana e afrodescendente na cultura brasileira. In: EDUCAÇÃO, Ministério da. Secretaria da Educação Continuada, Alfabetização e Diversidade. História da educação do negro e outras histórias. Brasília: SECAD, 2005, p. 249-274.

DELVAL, Juan. Aprender na vida e aprender na escola. Trad. Jussara Rodrigues. Porto Alegre: Artmed Editora, 2001.

GALVÃO, Ana Maria de Oliveira; BATISTA, Antonio Augusto Gomes. Oralidade e escrita: uma revisão. Cadernos de Pesquisa. São Paulo, n. 128, v. 36, p. 403-432, Mai./Ago. 2006.

GOMES, Nilma Lino. Diversidade e currículo. In: BEAUCHAMP, Jeanet; PAGEL, Sandra Denise; NASCIMENTO, Aricélia Ribeiro do. (Org.). Indagações sobre o currículo: diversidade e currículo. Brasília: Ministério da Educação, Secretaria de Educação Básica, 2007, p. $17-47$.

GROSFOGUEL, Ramón. Dilemas dos estudos étnicos norte-americanos: multiculturalismo identitário, colonização disciplinar e epistemologias descoloniais. Trad. Flávia Gouveia. $C i$ ência e Cultura, v. 59, n. 2, p. 32-35, São Paulo, abr./jun. 2007.

HAMPATÉ BÂ, Amadou. Amkoullel: o menino fula. São Paulo: Palas Athena: Casa das Áfricas, 2003.

HAMPATÉ BÂ, Amadou. A tradição viva. In: KI-ZERBO, Joseph (Ed.). História geral da África, I: Metodologia e pré-história da África. 2.ed. rev. Brasília: UNESCO, 2010, p. 167212.

LOBATO, Monteiro. Histórias da Tia Nastácia. 21. ed. São Paulo: Brasiliense, Brasília: INL, 1982.

MARCUSCHI, Luiz Antônio. Oralidade e escrita: uma ou duas leituras do mundo? Linha d'Água, n. 15, p. 41-62, Set. 2001.

MARTINS, Leda Maria. A oralitura da memória. In: FONSECA, Maria Nazareth Soares (Org.). Brasil afro-brasileiro. 2. ed., 1. reimp. Belo Horizonte: Autêntica, 2006, p. 61-86.

SOARES, Magda. Alfabetização e cidadania. In: Idem. Alfabetização e letramento. São Paulo: Contexto, 2003, p. 55-60.

Recebido em 6 de agosto de 2015.

Aceito em 5 de setembro de 2015. 
